\title{
DETERMINING THE AMOUNT OF EXPLOSIVES IN METAL FORMING
}

\author{
Darko Šunjić \& Stipo Buljan
}
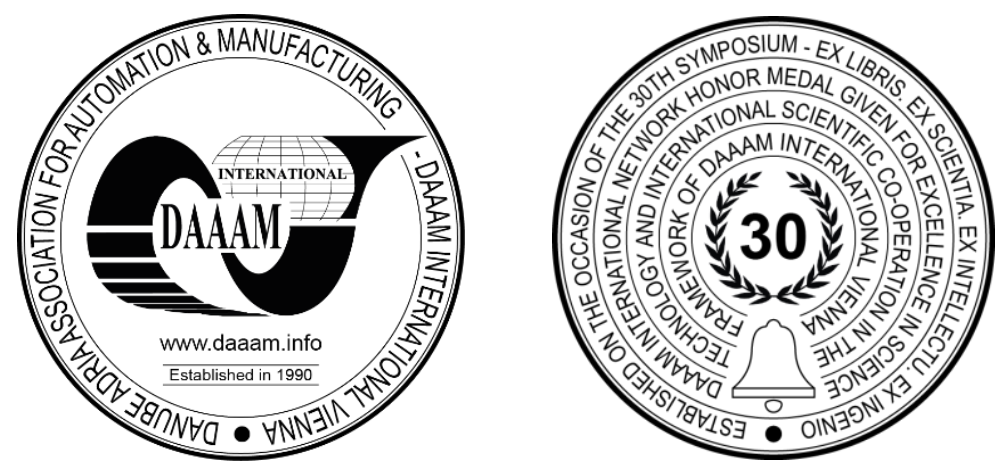

This Publication has to be referred as: Sunjic, D[arko] \& Buljan, S[tipo] (2019). Determining the Amount of Explosives in Metal Forming, Proceedings of the 30th DAAAM International Symposium, pp.0592-0598, B. Katalinic (Ed.), Published by DAAAM International, ISBN 978-3-902734-22-8, ISSN 1726-9679, Vienna, Austria DOI: $10.2507 / 30$ th.daaam.proceedings.080

\begin{abstract}
Explosive forming is an unconventional metal forming technology first discovered in the late $19^{\text {th }}$ century and had large development in the mid-20 th century. Explosives can be used as an energy source with technologies such as deep drawing, welding, expansion, blanking, and piercing, etc. In order to perform the forming process correctly, it is necessary to precisely determine the proper amount of explosives. The paper presents a review of the analytical methods used to calculate the amount of explosives required for forming a hemisphere. Three cases were taken for research with different thicknesses $(3,4$ and $5 \mathrm{~mm})$ and with a radius of $95 \mathrm{~mm}$. A comparison of the results obtained by these methods was also done.
\end{abstract}

Keywords: explosive forming; explosives; unconventional metal forming

\section{Introduction}

For over 140 years scientists use explosives for metal forming. It is noted that first usage of explosives for metalworking was in 1878 when Daniel Adamson of Manchester in the United Kingdom used explosive to test the strength of boilerplates[1]. In 1888 Charles Monroe performed the first experiment using an explosive to form a plate. The greater use of explosive energy appeared in the 1960s and at that time experimental researches are mostly done for aerospace industry needs for new workpieces with larger dimensions and complex geometries. In 1960s government financed simultaneously 80 projects [2].

Explosive forming represents one of the high velocity forming processes that can be combined with other technologies such as deep drawing, welding, engraving, hardening, etc. as shown in Figure 1. [3], [4], [5], [6]. If brisant explosives are used for forming process then it is called a high-velocity process because a whole forming process finishes in $1 \mu \mathrm{s}$ and with the use of gunpowder the process finishes in $1 \mathrm{~ms}$ and that is considered as velocity forming process. The impact wave, created with explosion of the explosive, transfer on blank. Blank is set on forming die. Explosive is positioned in vessel filled with water, while the blank is on the die and its press with blank holder [7]. The die can be made from metal, wood or ferroconcrete, and it has an exhaust outlet with vacuum hose which is used to release air from the die. This is because compaction of the air, at high speed of sheet metal deformation, can lead to unintended consequences and the appearance of debris during processing [8]. 


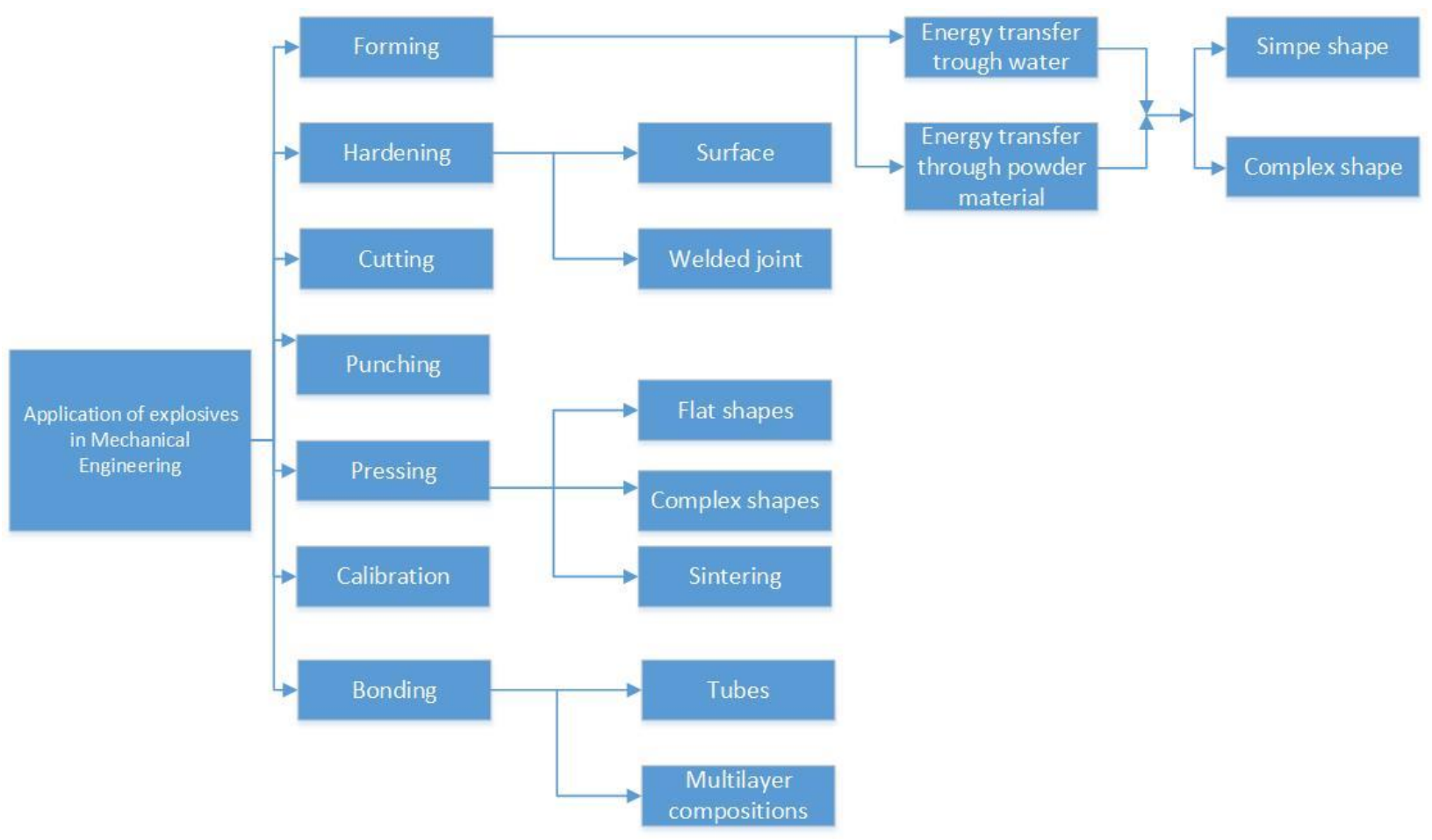

Fig. 1. Application of explosives in mechanical engineering

Explosive forming was the result of the need for:

- forming large-size elements when the dimensions of the workpiece and its configuration exceeds the capabilities of classic hydraulic or other presses;

- the development of new forming methods for the processing of complex elements from materials that have characteristics that are difficult to process, such as spacecraft elements;

- increasing the usability and cost-effectiveness in terms of small-scale production;

- reducing the number of deep drawing operations and increasing the accuracy and quality of production.

The main disadvantages of explosion forming are uneconomic in terms of mass and batch production, the "inappropriateness" of managing the forming process, and the insecurity of handling explosive material [9]. The shock wave pressure generated by the explosive charge ranges from a few hundred to several thousand MPa and it develops in $1 \mu \mathrm{s}$ or $1 \mathrm{~ms}$. Medium in all three aggregates can be used in the forming process, but water is most commonly used because of its availability and cost. In addition to water, oil can be also used as liquid media. From solid media, salt and sand can be used while air is used as gaseous media. The energy efficiency rate in the aqueous medium is $33 \%$ and in the air medium 4\% [10]. With increasing media density, the degree of energy efficiency increases. Explosive forming does note replace conventional static metal forming methods but merely complements them [11]. Also, this technology often allows faster prototyping and selection of new products and greater freedom for designers to choose materials in the structure itself. The size of the workpiece cannot be an obstacle in the application of this process (the possibilities regarding the workpiece dimensions are practically unlimited). The aggravating circumstances for the use of explosives are the need for specially trained personnel to work with explosives, adequate working space, storage space for explosives, adherence to standard operating procedures for the use of explosives for these purposes, but with the advancement of technology, these aggravating circumstances have been greatly reduced.

\section{Explosives as an energy source}

Explosives are the materials that can rapidly decompose chemically, produce extremely high pressure, and release a huge amount of energy at a moment [12]. For example, a good solid explosive converts energy at a rate of 1010 watts per square centimeter of its detonation front. Upon detonation, an explosive can produce a pressure over $20 \mathrm{GPa}$ and a temperature above $3000^{\circ} \mathrm{C}$ [13]. Explosives are not only powerful but also cheap, compared to many other types of energy.

The historical development of explosives is very long. Greece fire was used in the $7^{\text {th }}$ century and it was probably mixture of naphtha, quicklime, and sulphur [1]. After that, during $9^{\text {th }}$ century black powder or gunpowder was invented in China and it was water sensitive, created large amount of black smoke and hasn't much strength. Besides these 
disadvantages, gunpowder was probably most famous and commonly used until the development of nitroglycerin in $19^{\text {th }}$ century, by Italian scientist Ascari Sobrero. In 1862. Sweedish innovator Immanuel Nobel created method of industrial production of nitroglycerin. A few years after that, his son Alfred Nobel created first detonator - metal capsule filled with mercury fulminate $(\mathrm{Hg}(\mathrm{CNO}) 2)$ and that was a way to control explosives [14].

Explosives can be divided into three groups:

- Primary explosives are very sensitive on friction, impact or temperature rise. They detonate under the impact of external influences and therefore are used to charge electrical and nonelectrical detonators [15], [16].

- Secondary explosives are commonly used in industry and they need primary explosion to explode. The most known representative of this group of explosives is TNT.

- Tercyary explosives hardly explode in normal conditions and if particular conditions are fulfilled, explosives from this group can be classed as nonexplosives. The most common tertiary explosive in ammonium nitrate (AN). Most AN-based commercial explosives such as ANFO, water gels, and emulsions belong to tertiary explosives [17].

The detonators can be divided into three groups: electrical, non-electrical and electronic, as shown of Fig.2. In the case of electrical detonators, the initiation impulse is transmitted through the network of conductors to the electrical detonators. This initiation impulse is current, direct or alternating current. A common feature of today's standard electrical systems is that they are sensitive to external influences: stray currents, atmospheric discharges, electromagnetic fields, etc. The non-electrical system uses a chemical reaction of explosive (detonation) placed continuously inside the conductor as a small diameter explosive charge. These systems are not as sensitive as electrical, so they are safer to use.

Electronic detonators were developed in the 1990s. In these detonators, there is a computer chip to control delay time using electrical energy that is stored in one or more capacitors for initiation energy or timing clock. In this case, delay time is achieved electronically [18].

Unlike these three types of detonators, the detonating cord can be taken as a flexible detonator because it is adaptable, inexpensive, safe to use in external electrical environments. Modern detonating cords have PETN cotton core surrounded by a variety of textile combinations, plastics and waterproofing materials, with a burning speed exceeding 7000 m/s [19] $[1]$.

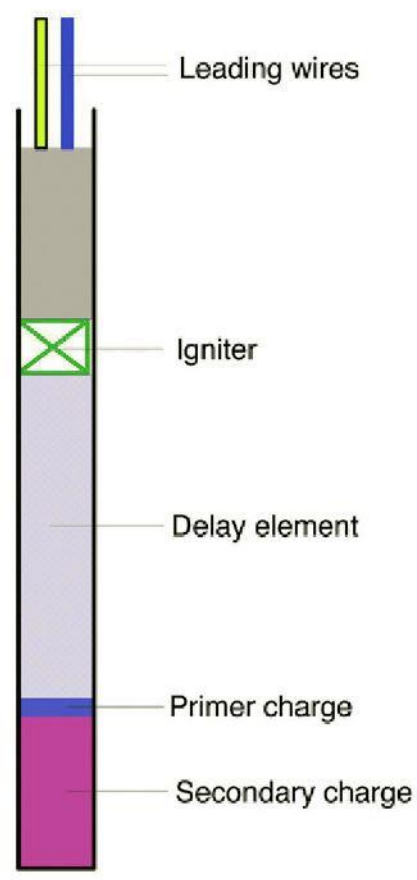

(a)

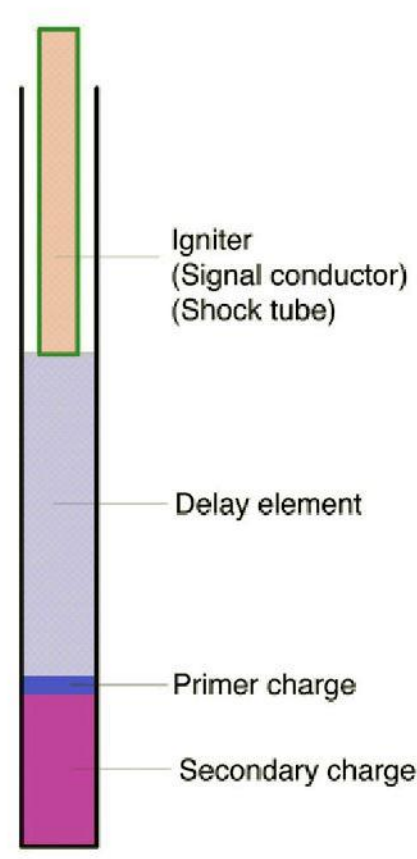

(b)

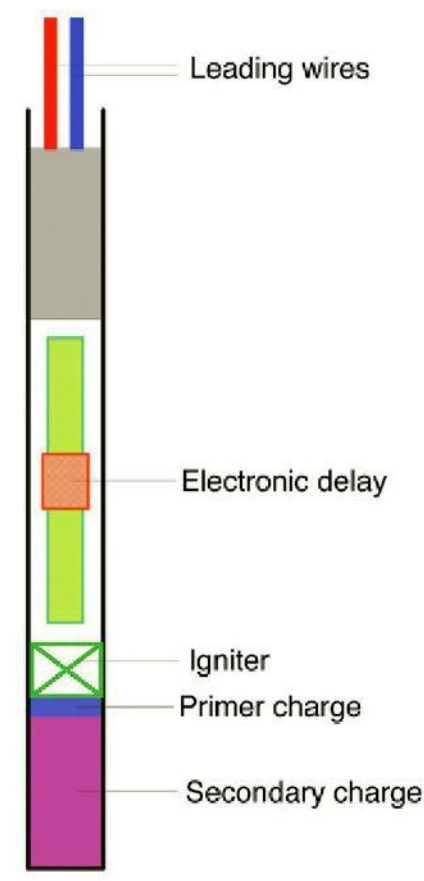

(c)

Fig. 2. Three types of detonators

\section{Analytical methods for calculation of explosive mass}

In order to perform the experiment correctly, it is necessary to determine all the factors involved in the process. One of the factors is the determination of the required mass of explosives. If less than necessary explosive is used, the 
workpiece will not form properly. Otherwise, using too much explosives will result in the destruction of the workpiece and, most likely, the mold, and the system involved in the experiment. The following describes the analytical calculation of the required mass of explosives, for example, the development of a hemisphere thickness of 3,4 and 5 mm and a radius of $95 \mathrm{~mm}$ from material St 14, as shown of Fig. 3.

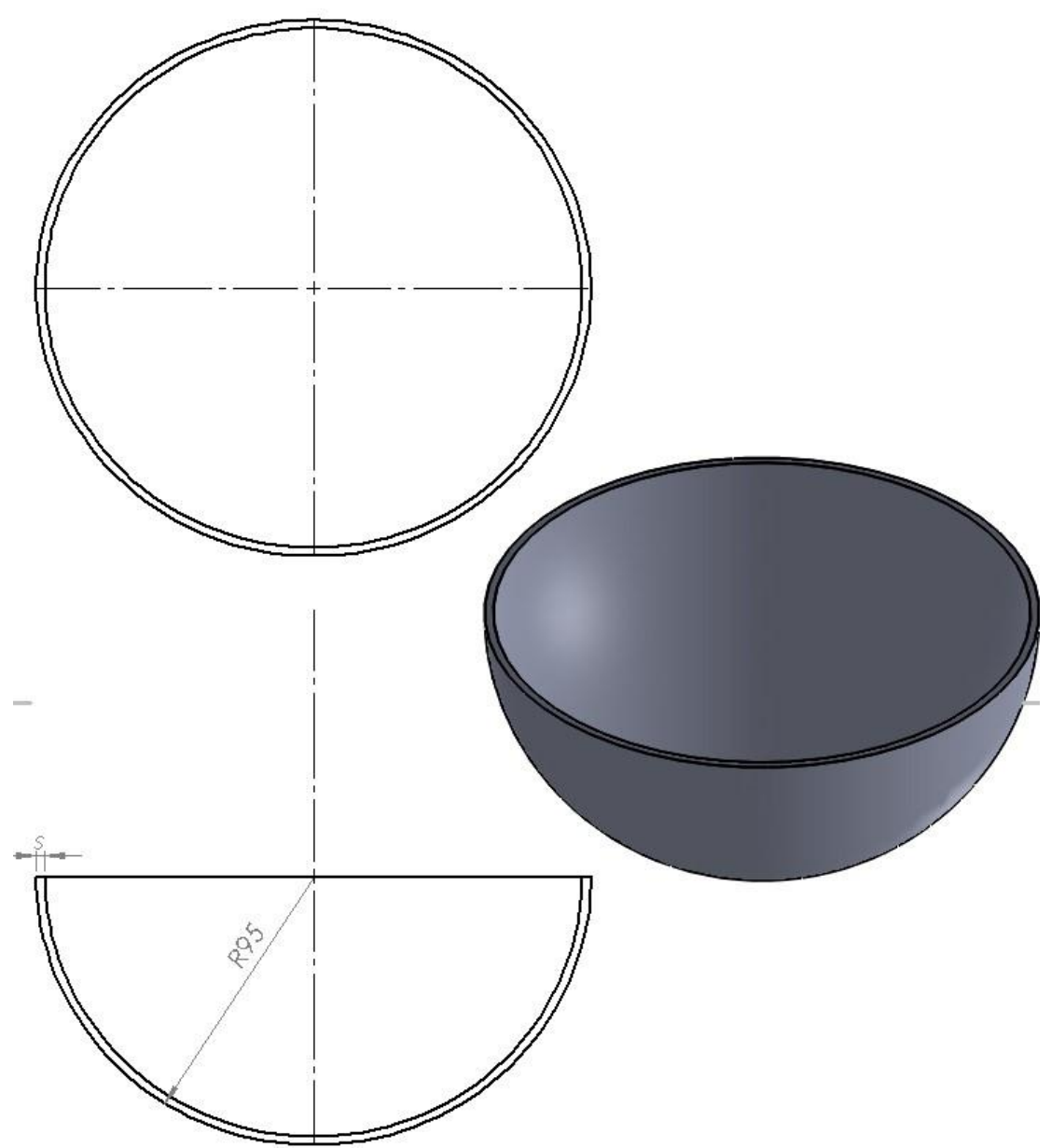

Fig. 3. Hemisphere

One of the formulas used to calculate the required mass of explosives:

$G=\frac{\Pi D^{2} \delta B}{e^{(1-\cos \varphi)(1+\alpha)}}\left\{2 \ln \left[1,5 \frac{1}{2\left(1+\frac{4 f^{2}}{D^{2}}\right)}\right]\right\}^{(\alpha+1)}$

where $\mathrm{G}$ - calculated mass of explosives, $\mathrm{D}$ - diameter of die aperture $(\mathrm{mm}), \delta$ - sheet thickness $(\mathrm{mm}), \beta$ and $\alpha-$ coefficient of approximation of real stress curves: $\alpha=0,24$ for Al alloys and $\beta=327, \mathrm{f}-$ die depth (mm), $\varphi-$ the angle between the die and the explosive charge [20]. In addition to this formula, it can also be used:

$$
G=0,0113 \delta^{0,972} K^{4,134} R^{0,582}
$$

where $\mathrm{G}$ - calculated mass of explosives, $\delta$ - sheet thickness (mm), K - the coefficient of drawing for the blank material and the distance $\mathrm{R}$ between the explosive charge and the workpiece [10]. This value is multiplied by the surface of the wetted part of the workpiece. The mass of the explosive can be determined by an expression that depends on the tensile strength of the sheet $\sigma_{\mathrm{m}}[10]$ :

$$
G=2,69 \cdot 10^{-5} \sigma_{m}\left(\delta^{0,233} K R^{0,14}\right)^{4,134}
$$

After calculating the required masses, we obtained the following results: 


$$
\begin{aligned}
& G=\frac{\Pi D^{2} \delta B}{e^{(1-\cos \varphi)(1+\alpha)}}\left\{2 \ln \left[1,5-\frac{1}{2\left(1+\frac{4 f^{2}}{D^{2}}\right)}\right]\right\}^{(\alpha+1)} \\
& =\frac{\Pi \cdot 0,190^{2} \cdot 0,003 \cdot 1900}{e^{\left(1-\cos 52^{\circ}\right)(1+0,16)}}\left\{2 \ln \left[1,5-\frac{1}{2\left(1+\frac{4 \cdot 0,095^{2}}{0,190^{2}}\right)}\right]\right\}^{(0,16+1)}=0,162353 \mathrm{~kg}=162 \mathrm{~g} \\
& G=\frac{\Pi D^{2} \delta B}{e^{(1-\cos \varphi)(1+\alpha)}}\left\{2 \ln \left[1,5-\frac{1}{2\left(1+\frac{4 f^{2}}{D^{2}}\right)}\right]\right\}^{(\alpha+1)} \\
& =\frac{\Pi \cdot 0,190^{2} \cdot 0,004 \cdot 1900}{e^{\left(1-\cos 52^{\circ}\right)(1+0,16)}}\left\{2 \ln \left[1,5-\frac{1}{2\left(1+\frac{4 \cdot 0,095^{2}}{0,190^{2}}\right)}\right]\right\}^{(0,16+1)}=0,216471 \mathrm{~kg}=216 \mathrm{~g} \\
& G=\frac{\Pi D^{2} \delta B}{e^{(1-\cos \varphi)(1+\alpha)}}\left\{2 \ln \left[1,5-\frac{1}{2\left(1+\frac{4 f^{2}}{D^{2}}\right)}\right]\right\}^{(\alpha+1)} \\
& =\frac{\Pi \cdot 0,190^{2} \cdot 0,005 \cdot 1900}{e^{\left(1-\cos 52^{\circ}\right)(1+0,16)}}\left\{2 \ln \left[1,5-\frac{1}{2\left(1+\frac{5 \cdot 0,095^{2}}{0,190^{2}}\right)}\right]\right\}^{(0,16+1)}=0,270589 \mathrm{~kg}=270 \mathrm{~g}
\end{aligned}
$$

\begin{tabular}{|c|c|}
\hline Sheet thickness $\boldsymbol{\delta}(\mathbf{m m})$ & Explosive mass (g) \\
\hline 3 & 162 \\
\hline 4 & 216 \\
\hline 5 & 270 \\
\hline
\end{tabular}

Table 1. Required explosive mass (1)

$$
\begin{aligned}
& G=0,0113 \cdot \delta^{0,972} \cdot K^{4,134} \cdot R^{0,582}=0,0113 \cdot 3^{0,972} \cdot 0,7^{4,134} \cdot 76^{0,582}=0,09356 \\
& G=0,09356 \cdot P=0,09356 \cdot 0,2268=0,0212 \mathrm{~kg}=21,2 \mathrm{~g} \\
& G=0,0113 \cdot \delta^{0,972} \cdot K^{4,134} \cdot R^{0,582}=0,0113 \cdot 4^{0,972} \cdot 0,7^{4,134} \cdot 76^{0,582}=0,12375 \\
& G=0,12375 \cdot P=0,12375 \cdot 0,2268=0,028 \mathrm{~kg}=28 \mathrm{~g} \\
& G=0,0113 \cdot \delta^{0,972} \cdot K^{4,134} \cdot R^{0,582}=0,0113 \cdot 5^{0,972} \cdot 0,7^{4,134} \cdot 76^{0,582}=0,1537 \\
& G=0,1537 \cdot P=0,1537 \cdot 0,2268=0,03486 \mathrm{~kg}=34,8 \mathrm{~g}
\end{aligned}
$$

\begin{tabular}{|c|c|}
\hline Sheet thickness $\boldsymbol{\delta}(\mathbf{m m})$ & Explosive mass $(\mathbf{g})$ \\
\hline 3 & 21,2 \\
\hline 4 & 28 \\
\hline 5 & 34,8 \\
\hline
\end{tabular}

Table 2. Required explosive mass (2)

$$
\begin{aligned}
& G=2,69 \cdot 10^{-5} \sigma_{m}\left(\delta^{0,233} K R^{0,14}\right)^{4,134}=2,69 \cdot 10^{-5} \cdot 310\left(3^{0,233} \cdot 0,7 \cdot 76^{0,14}\right)^{4,134}=0,067 \\
& G=0,067 \cdot P=0,067 \cdot 0,2268=0,015 \mathrm{~kg}=15 \mathrm{~g} \\
& G=2,69 \cdot 10^{-5} \cdot \sigma_{m}\left(\delta^{0,233} \cdot K \cdot R^{0,14}\right)^{4,134}=2,69 \cdot 10^{-5} \cdot 310\left(4^{0,233} \cdot 0,7 \cdot 76^{0,14}\right)^{4,134}=0,889 \\
& G=0,889 \cdot P=0,889 \cdot 0,2268=0,0201 \mathrm{~kg}=20,1 \mathrm{~g}
\end{aligned}
$$


$G=2,69 \cdot 10^{-5} \sigma_{m}\left(\delta^{0,233} K R^{0,14}\right)^{4,134}=2,69 \cdot 10^{-5} \cdot 310\left(5^{0,233} \cdot 0,7 \cdot 76^{0,14}\right)^{4,134}=0,1102$

$G=0,1102 \cdot P=0,1102 \cdot 0,2268=0,0250 \mathrm{~kg}=25 \mathrm{~g}$

\begin{tabular}{|c|c|}
\hline Sheet thickness $\boldsymbol{\delta}(\mathbf{m m})$ & Explosive mass (g) \\
\hline 3 & 15 \\
\hline 4 & 20 \\
\hline 5 & 25 \\
\hline
\end{tabular}

Table 3. Required explosive mass (3)

The obtained results are shown graphically, where in Fig. 4 are the results for a workpiece with a thickness of $3 \mathrm{~mm}$, in Fig. 5. are the results for a $4 \mathrm{~mm}$ thickness hemisphere and in Fig. 6 is shown the required explosive masses for a 5 $\mathrm{mm}$ thickness hemisphere.

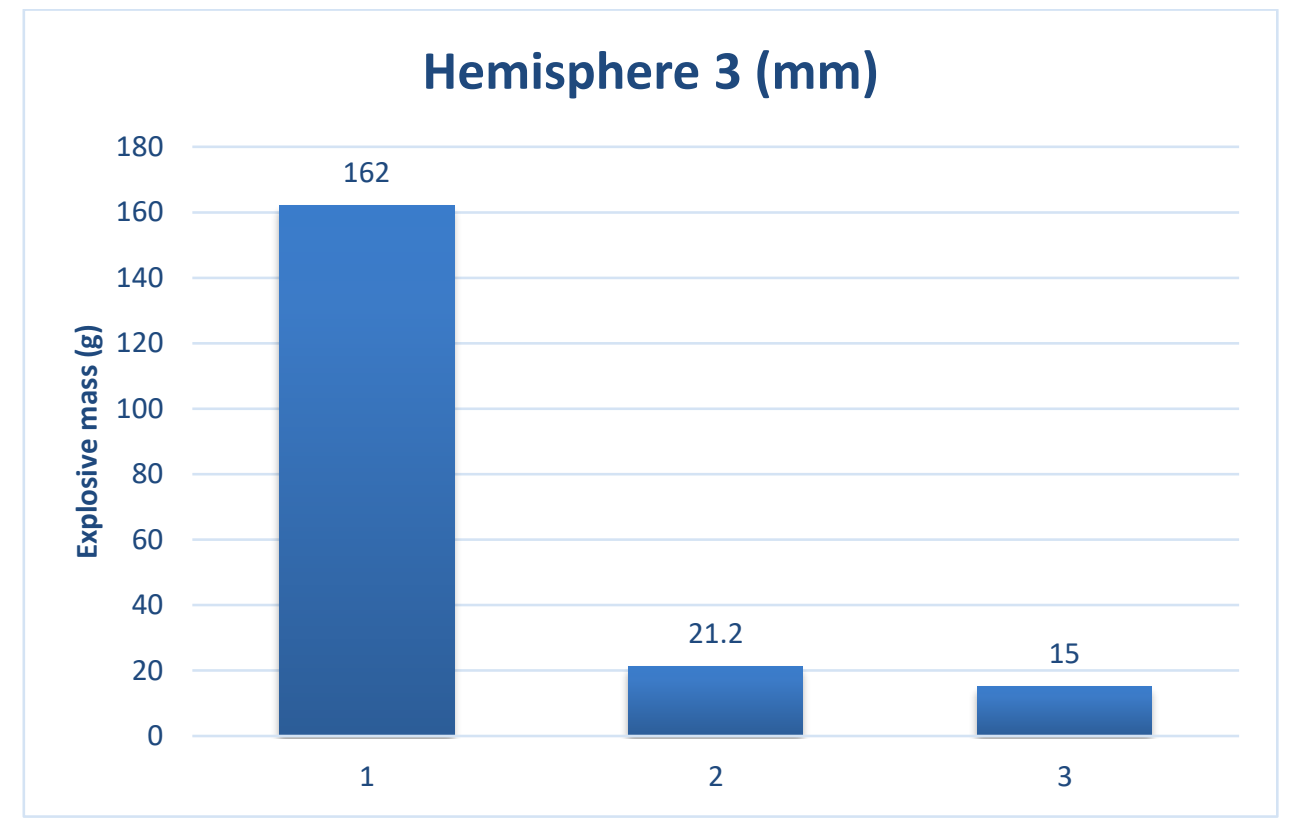

Fig. 4. The mass of explosives required to form a $3 \mathrm{~mm}$ hemisphere

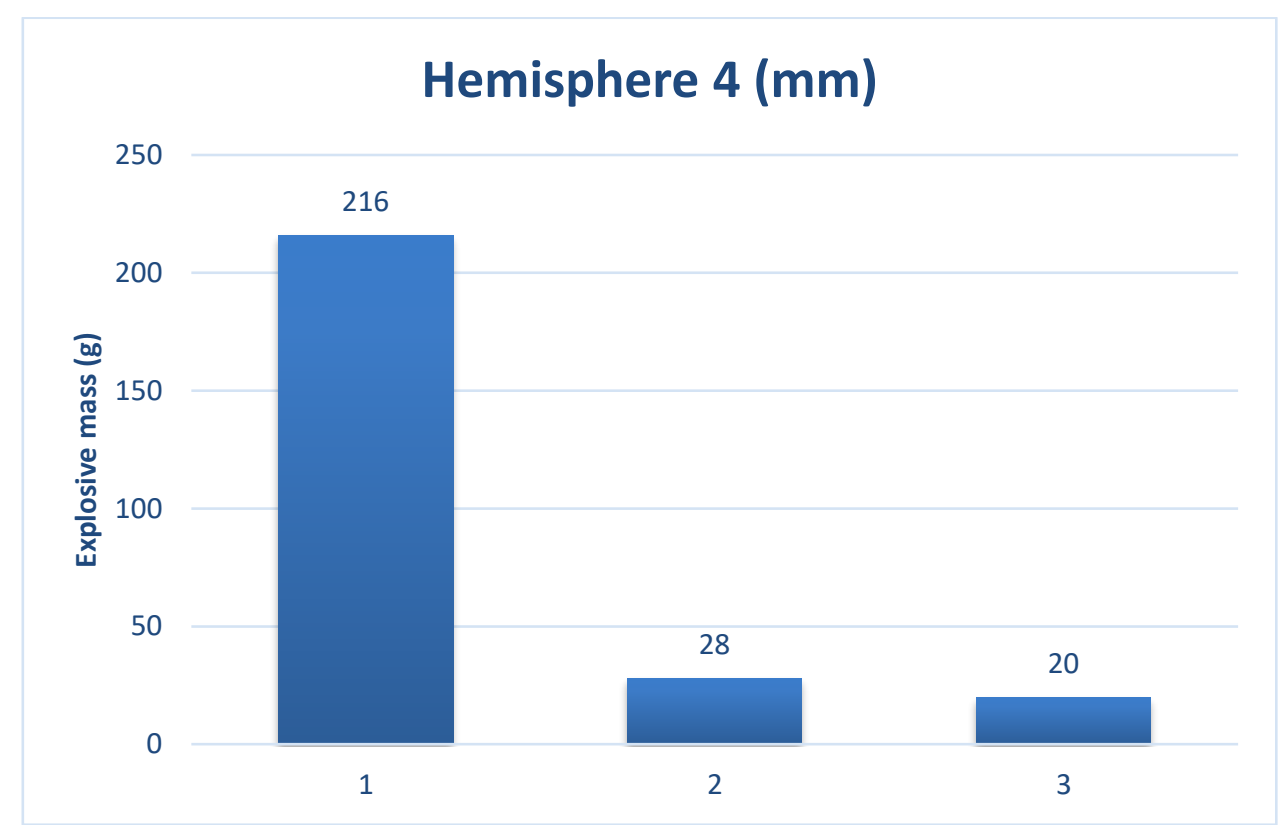

Fig. 5. The mass of explosives required to form a $4 \mathrm{~mm}$ hemisphere 


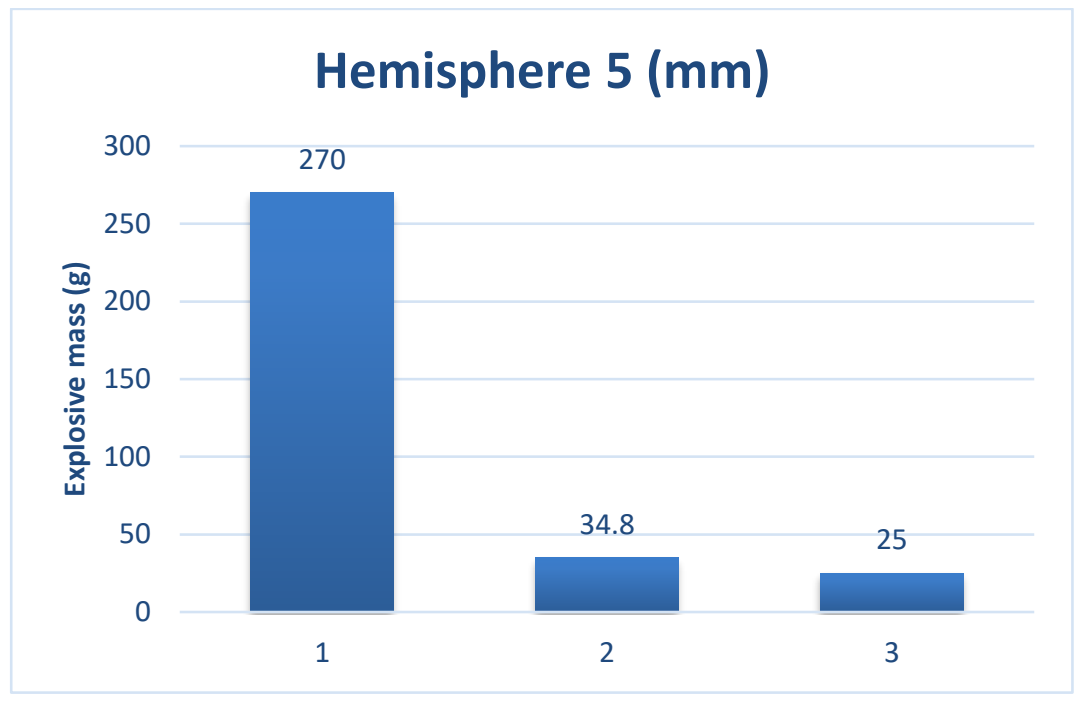

Fig. 6. The mass of explosives required to form a $5 \mathrm{~mm}$ hemisphere

\section{Conclusion}

In this paper is presented comparisons of analytical results of obtaining the required mass of explosives for a hemisphere of different wall thicknesses. Using (1), the highest results were obtained up to $270 \mathrm{~g}$ for $5 \mathrm{~mm}$ hemisphere. Significantly smaller results were obtained using (2) 34,8 g and using (3) $25 \mathrm{~g}$. Comparing these results, we find that there are too many discrepancies between certain formulas and that there is no unified formula for this process. During the experiment, it is necessary to start processing with the smallest amount of explosives and gradually increase it in order not to destroy the workpiece, tools and therefore the experiment. Explosive forming technology is constantly being improved. The number of metals formed with this unconventional method is increasing and finished and semi-finished products have better properties. In the future, this technology should continue to be researched and improved in the field of analytical and theoretical principles.

\section{References}

[1] Zhang, Z.-X. (2016). Rock fracture and blasting: theory and applications. Butterworth-Heinemann.

[2] Mynors, D. J., \& Zhang, B. (2002). Applications and capabilities of explosive forming. Journal of Materials Processing Technology, 125-126(March), 1-25. https://doi.org/10.1016/S0924-0136(02)00413-2

[3] Buljan, S., Đukić, H., \& Šunjić, D. (2018). Application of Explosive Energy in Metal Forming Technologies. In D. Golubović, A. Košarac, \& D. Jeremić (Eds.), Conference on Mechanical Engineering Technologies and Applications (pp. 139-144). Jahorina: University of East Sarajevo Faculty of Mechanical Engineering East Sarajevo.

[4] Turna, M., Ondruska, J., Sahul, M., \& Turnova, Z. (2011). Proposal of welding technology for trimetal production. Annals of DAAAM \& Proceedings, 835-837.

[5] Masek, B., Urbanek, M., Hronek, P., \& Nesvadba, P. (2010). Alternative explosion-formed joint of high-strength tube and sleeve. na.

[6] Yang, M., Ma, H., \& Shen, Z. (2019). Study on explosive welding of Ta2 titanium to Q235 steel using colloid water as a covering for explosives. Journal of Materials Research and Technology.

[7] Bhaduri, A. (2018). Mechanical Properties and Working of Metals and Alloys (Vol. 264). Springer.

[8] Buljan, S. (2007). Primjena genetskih i stohastičkih metoda u istraživanju procesa dubokog vučenja eksplozijom. Fakultet strojarstva i računarstva.

[9] Šunjić, D., \& Buljan, S. (2018). Application of Explosives in Metal Forming. In International Conference "New Technologies, Development and Applications" (pp. 144-148). Springer.

[10] Đukić, H., \& Nožić, M. (2013). Obrada deformisanjem. MF Mostar.

[11] Dukic, H., Nozic, M., \& Sunjic, D. (2017). Temperature influence on the drawing process stability with the reduction of the wall thickness. Annals of DAAAM \& Proceedings, 708-714.

[12] Suceska, M. (2012). Test methods for explosives. Springer Science \& Business Media.

[13] Fickett, W., \& Davis, W. C. (2000). Detonation: theory and experiment. Courier Corporation.

[14] Johansson, C. H., \& Persson, P.-A. (1970). Detonics of high explosives. Academic Press.

[15] Matyáś, R., \& Pachman, J. (2013). Primary explosives. Springer.

[16] Ester, Z. (2005). Miniranje I, eksplozivne tvari, svojstva i metode ispitivanja.

[17] Savić, M. (1998). Miniranje na površinskim kopovima. RTB, Institut za bakar.

[18] Cardu, M., Giraudi, A., \& Oreste, P. (2013). A review of the benefits of electronic detonators. Rem: Revista Escola de Minas, 66(3), 375-382.

[19] Eckhoff, R. K. (2016). Explosion hazards in the process industries. Gulf Professional Publishing.

[20] Pavelić, V. (1995). Specifične tehnologije u proizvodnji oružja. Ministarstvo obrane Republike Hrvatske. 